\title{
Dietary patterns of Chinese women of childbearing age during pregnancy and their relationship to the neonatal birth weight
}

Hui Yan', Shaonong Dang ${ }^{2}$, Yaodong Zhang ${ }^{1 *}$ and Shuying Luo ${ }^{1}$

\begin{abstract}
Objective: To examine the type of maternal dietary patterns during pregnancy and the distribution characteristics of children's birth weight and the association between dietary patterns and neonatal birth weight in China.

Methods: Data were derived from a cross-sectional program named "The prevalence and risk factors of birth defects in Shaanxi Province" in July to November in 2013. A stratified multistage random sampling method was used to select women and their children. The mother's diet during pregnancy was investigated using semiquantitative food frequency questionnaire (FFQ) to collect the frequency and amount of food consumption, and the newborn birth weight as well as related social demographic information was collected at the same time. In our study, 0-1 year old children and their mothers with complete dietary survey data were selected as research objects. The main dietary patterns were identified according to factor analysis, and latent class analysis (LCA) was used to investigate the social demographic factors affecting dietary patterns. The logistic regression model was used to assess the association between birth weight and maternal dietary patterns during pregnancy by establishing three adjusting models and the data were stratified for further analysis by urban-rural and regions.
\end{abstract}

Results: A total of 15,980 participants were involved in this study. Four dietary patterns were identified: "vegetarian pattern", "balance pattern", "traditional pattern" and "processing pattern". Compared with moderate tertile, women in the highest tertile of adherence to vegetarian pattern increased the risk of low birth weight in offspring in rural areas $(O R=1.61,95 \% C l: 1.06-2.93)$ and middle region $(O R=1.75,95 \% C l: 1.18-2.62)$, and the traditional pattern had greater odds of lower birth weight in the middle region $(O R=1.55,95 \% \mathrm{Cl}: 1.05-3.75)$. The processing pattern was found a protective factor for the occurrence of low birth weight in rural areas $(O R=0.98,95 \% C l: 0.43-0.99)$ but was a risk factor for low birth weight in the southern region $(O R=8.83,95 \% C l: 1.22-15.16)$. The balance pattern was a protective factor for the occurrence of low birth weight in the northern region( $O R=0.35,95 \%$ Cl:0.14-0.83).

(Continued on next page)

\footnotetext{
* Correspondence: etyylclxbx@163.com

'The Children's Hospital Affiliaten to Zhengzhou University; Henan Children's Hospital, Zhengzhou Children's Hospital, Zhengzhou 450018, China

Full list of author information is available at the end of the article
}

(c) The Author(s). 2020 Open Access This article is licensed under a Creative Commons Attribution 4.0 International License, which permits use, sharing, adaptation, distribution and reproduction in any medium or format, as long as you give appropriate credit to the original author(s) and the source, provide a link to the Creative Commons licence, and indicate if changes were made. The images or other third party material in this article are included in the article's Creative Commons licence, unless indicated otherwise in a credit line to the material. If material is not included in the article's Creative Commons licence and your intended use is not permitted by statutory regulation or exceeds the permitted use, you will need to obtain permission directly from the copyright holder. To view a copy of this licence, visit http://creativecommons.org/licenses/by/4.0/ The Creative Commons Public Domain Dedication waiver (http://creativecommons.org/publicdomain/zero/1.0/) applies to the data made available in this article, unless otherwise stated in a credit line to the data. 
(Continued from previous page)

Conclusion: The vegetarian and traditional pattern may be positively related to a higher risk of low birth weight while the balanced pattern may keep birth weight of offspring within the appropriate range. Health education of balanced diet and individual nutrition guidance during pregnancy should be strengthened, to make the dietary structure during pregnancy are more reasonable, reduce the occurrence of adverse birth weight of newborns.

Keywords: Pregnant women, Dietary pattern, Birth weight, Cross-sectional studies

\section{Introduction}

Pregnancy is a complex physiological process, the health of pregnant women and offspring is affected by nutrition during pregnancy. Reasonable and correct dietary structure is the guarantee for improving the quality of the population [1]. The dietary nutrition evaluation of pregnant women was concentrated on the quantitative intake of certain nutrients or specific foods in previous study [2]. The different nutrients contained in each food have intricate interactions in the digestion, absorption and metabolism of the body [3], while the dietary pattern during pregnancy may more fully evaluate the relationship between dietary nutrition and pregnancy outcomes. Dietary pattern is a semi-quantitative research method, but it is suitable for large-scale epidemiological research [4]. In recent years, it has gradually become an important method to explore the dietary nutrition and healthy outcome. The analysis of the overall dietary status can better reflect people's actual eating conditions and predict the risk of disease [5-7]. For example, Arkkola T [8] analyzed nutritional status during pregnancy, obtained and named 7 dietary patterns in Finland, which largely explained the changes of energy and most nutrients in pregnant women, and the age and education level of pregnant women were correlated with dietary patterns. In addition to reflecting nutrient intake, dietary patterns were also used to analyze associations with pregnancy outcomes. There were few studies on the relationship between dietary patterns of women during pregnancy and neonatal birth weight, and some of the results of these studies were inconsistent. A cohort study from Denmark [9] found that pregnant women in the "Western" diet group were more likely to deliver low birth weight newborns, increasing the risk of small for gestational age (SGA); while pregnant women in the "healthconscious" and "intermediate" groups was associated with a lower incidence of SGA. A survey from the Auckland region of New Zealand found that pregnant women with higher scores on "traditional" dietary patterns had a lower risk of SGA [10]. A study from Norway found that women with a high prudent diet gave birth to babies with significantly lower birth weight and that women with a high traditional diet gave birth to babies with significantly higher birth weight. Moreover, being in the high prudent group was associated with an increased risk of SGA and decreased risk of larger for gestational age (LGA), in comparison with being in the high Western group [11].

However, there are few research data in this aspect in China at present, and the dietary pattern has a strong local specialties and is influenced by many aspects. Chinese pregnant women have complex and diverse eating behaviors, and follow a set of dietary customs which are not extensively explored in the literature. For this reason, a large-scale population survey was conducted in Shaanxi, China. From a macro perspective, the main dietary patterns of women of childbearing age during pregnancy were analyzed, and the possible confounding factors were adjusted to further explore the relationship between dietary patterns and birth weight, SGA and LGA. Information about how maternal food quality is correlated to unfavorable birth weight can provide a basis for nutritional interventions to improve both maternal and infant health in western China.

\section{Materials and methods}

\section{Sources and subjects}

The data were derived from a cross-sectional program named "The prevalence and risk factors of birth defects in Shaanxi Province", which was the Sub-topics of National Natural Science Foundation of China project "The primary preventive effect of micronutrient intervention on the occurrence of congenital heart disease during perinatal period and its mechanism", which were collected from July to November in 2013. A stratified multistage random sampling method was used to carried on sampling, random sampling of districts and counties was carried out after stratification by urban and rural areas. According to the urban-rural ratio and taking into account the population intensity and fertility level, 10 urban districts and 20 counties were randomly selected. The difference between urban and rural areas was determined according to the overall urban and rural population in Shaanxi, making the sample representative. The sampling methods were as follows: 1) 6 townships were randomly selected from the sample counties, and 6 villages were randomly selected from each township. Each village randomly surveyed 30 women aged 15-49 who were pregnant after 2010 and had a clear pregnancy outcome. 2) In each of the urban districts, 3 sub-district 
offices were randomly selected, and each district randomly selected 6 communities, each community randomly surveyed 60 eligible women of childbearing age. The subjects included women of childbearing age who had been pregnant between January 2010 to November 2013, met the inclusion criteria, had known outcome and informed consent. The inclusion criteria were that women were pregnant from 2010 to 2013, had no major diseases, were willing to participate in this study, and completed the questionnaire independently under the guidance of the investigator. The exclusion criteria were those with twin or multiple pregnancies, with severe memory impairment of dietary intake during pregnancy, and those with diabetes mellitus, severe heart, liver and kidney diseases and psychosis and impairment of understanding ability during gestation. The investigation was approved by the Medical Bioscience Research Ethics Committee of the Ministry of Medicine of Xi'an Jiaotong University (No. 2012008), and all respondents signed informed consent. In order to reduce the error caused by recall bias and increase the accuracy of the results, this study selected children aged between 0 and 1 year old and their mothers with a complete dietary survey data as subjects.

Data collection was conducted using the questionnaire "Status of Birth Defects and Risk Factors in Shaanxi Province". The content of questionnaire included: basic conditions of the mother, birth weight of the newborn, sociodemographic characteristics (family address, parent's name, contact information, mother's gestational age, past birth history, family history, parental age, parental ethnicity, parental marital status, parental residence territory, parental education, parental occupation, family monthly expenditure, mother's life behavior factors (smoking status, drinking status), etc., food frequency questionnaire (frequency and amount of food consumed by the mother during most recent pregnancy).

\section{Dietary survey}

Food intake was conducted by trained investigators using the semi-quantitative food frequency questionnaire (FFQ) [12]. Considering the consumption and frequency of food in the survey population, this dietary frequency questionnaire included 102 kinds of foods, including 13 kinds of staple foods, 19 kinds of animal protein foods, and 6 kinds of plant protein foods, 36 kinds of vegetables, 12 kinds of fruits, 3 kinds of nut foods, 5 kinds of drinks, and 8 kinds of snacks. After explaining the contents of the questionnaire to the respondents, the investigators uniformly recorded the frequency and amount of each type of food intake of the pregnant woman during the most recent pregnancy. Frequency was divided into: almost don't eat, <1 time/month, 1-3 times/ month, 1 time/week, 2-4 times/week, 5-6 times/week, 1 time/day, $\geq 2$ times/day; each intake was gram per time.
This questionnaire was developed based on the food frequency questionnaire of women of childbearing age in Shaanxi Province and verified by a 24 -h food review survey. The correlation coefficient between the two methods was $0.6 \sim 0.9$, suggesting that the questionnaire had certain reliability and validity [13].

\section{Newborn Birth Weight (g)}

Information about the birth wight of the newborn was collected mainly through birth certificates. When the newborn weight $<2500 \mathrm{~g}$, it was defined as low birth weight infant; when the newborn weight $\geq 4000 \mathrm{~g}$, it was defined as macrosomia; when the newborn birth weight $2500 \sim 4000 \mathrm{~g}$, it was defined as normal weight infant [14]. Referring to the revised report on the birth weight of newborns of different gestational ages in China, the newborns were divided into three categories according to the relationship between birth weight and gestational age: infants were defined as small for gestational age (SGA) when birth weight was below the 10th percentile $\left(\mathrm{P}_{10}\right)$ of the average gestational age; infants with birth weight above the 90th percentile $\left(\mathrm{P}_{90}\right)$ of the same gestational age were defined as larger for gestational age (LGA); between $\mathrm{P}_{10}$ and $\mathrm{P}_{90}$ of the same gestational age was appropriate for gestational age (AGA) [15].

\section{Quality Control}

Before the implementation of the investigation, a rigorous scientific research design was carried out, and a training manual for investigators was prepared, all investigators received unified training. A community or village was selected for pre-investigation to ensure that each investigator correctly understood each item of the investigation form, and participated in the on-site investigation with a certificate of quality. The completed questionnaires were collated and verified by the investigators. The questionnaires that didn't answer according to the regulations and had too many missing items were defined as invalid questionnaires, and the invalid questionnaires were excluded. After each county (district) completed the on-site investigation, $5 \%$ of the subjects were randomly selected for repeated investigation, and the results were reproducible to ensure the authenticity of the survey results.

\section{Statistical analysis}

The questionnaire data were inputted by Epidata 3.1, and the data was double-input. Due to regional differences in intake of food and nutrient, the analysis was conducted stratified according to women's location (urban/rural) and region(the southern, northern and middle region). The continuous variables were statistically described by mean $(\bar{x})$ and standard deviation (SD), median $(\mathrm{M})$ and quartile $\left(\mathrm{Q}_{1} \sim \mathrm{Q}_{3}\right)$; categorical variables 
were described by composition ratio and rate. For missing values, we used the mean padding method for processing. These analyses were performed with the use of SAS.9.1, SPSS18.0, Mplus6.0, the drawing process was carried out by Microsoft Office 2003 Excel and Visio software. $P$ values (two sided) $<0.05$ was considered statistically significant.

\section{Factor analysis}

In the establishment of the dietary pattern, taking into account the statistical efficiency, the similar foods with particularly small intakes were sorted and combined, and 102 foods were integrated into 31 food items including pasta, rice/porridge, pork, beef and mutton, chicken and duck meat, animals viscera, fish, shrimps and crabs, milk, soy products, vegetables, fruits, fungus, nuts, snacks and drinks. The main dietary patterns were identified according to Principal Component Analysis (PCA) and factor analysis [4]. All 31 food items were integrated into the analysis, the variance was used to maximize the orthogonal rotation to ensure that the factor was clear and the factor load was obtained. The selection of the number of factors was mainly based on: 1) eigen root> 1 ; 2 ) the gravel diagram indicated the main factor distribution; 3) interpretability of the extraction factor; 4) the proportion of factors explain variance, but only for reference (because this criterion was largely influenced by the number of variables included in the analysis) [16]. The naming of the factor was based on the characteristics of the food contained in the dietary pattern [17], and the factor was named after the food that best represents the nature of the factor; and according to the characteristics of the factor load, the food with an absolute value of more than 0.3 was selected for analysis.

All participants received factor scores for each dietary pattern, the scores of each dietary pattern were categorized into tertiles (Tertile1 (low score group), Tertile2 (middle score group) and Tertile3 (high score grouping)), the middle tertile (T2) score of each dietary pattern was considered to be the reference. The birth weight of the newborn was used as the dependent variable, and each classified individual dietary pattern was as an independent variable, the logistic regression model was used to investigate the association between birth weight and maternal dietary patterns during pregnancy, and the crude and multivariateadjusted $O R$ and 95\%CI were calculated. Covariates included infant gender; mother's age and gestational age, mother's residence; education level; husband's residence; family monthly expenditure; regional classification. Further stratified analysis according to the residence (urban, rural) and regional (the southern, northern and middle region).

\section{Latent class analysis (LCA)}

Firstly, Lo-Mendell-Rubin likelihood ratio test was used to determine the optimal number of LCA selections and compared with dietary patterns after extracting four dietary patterns by factor analysis. The most widely used signal evaluation indicators in the LCA was AIC criterion (akaike information criterion) and the BIC criterion (bayesian information criterion), both indicated that the smaller the value, the better the fit. In the LCA analysis, every women could predict a certain type of probability, and subjects could be grouped into the type of dietary pattern with the highest probability. Then the study mainly used the LCA method to calculate the intake of various foods in each dietary pattern, compared the sociodemographic characteristics and nutrient intake between the various dietary patterns, multiple tests were compared by anova, mann-whitney test and Bonferroni correction.

\section{Results \\ Baseline characteristics of subjects Maternal social demographic characteristics}

A total of 15,980 pregnant women who met the requirements were included in the study, aged 17 to 47 years $(27.6 \pm 4.5)$. There were $8501(53.2 \%)$ male infants and 7479 (46.8\%) female infants; they were aged between 0 to 12 months $(6.6 \pm 2.6)$, and the birth weight was 1050 $6250 \mathrm{~g}(3279.9 \pm 454.6 \mathrm{~g})$. The basic characteristics of the research object were shown in Table 1 .

\section{Newborn birth weight}

In this study, the average weight of newborns in urban areas was $3339.2 \pm 461.6 \mathrm{~g}, 3230.7 \pm 451.0 \mathrm{~g}$ in rural areas, $3263.7 \pm 453.3 \mathrm{~g}$ in southern Shaanxi, $3290.3 \pm$ $464.7 \mathrm{~g}$ in northern Shaanxi, and $3252.6 \pm 450.9 \mathrm{~g}$ in middle region. When there was no stratification, 783 newborns with birth weight of $<2500 \mathrm{~g}$, accounting for $4.9 \%$, and 703 newborns with birth weight $>4000 \mathrm{~g}$, accounting for $4.4 \%$; the incidence of SGA and LGA was 14.7 and $7.6 \%$, respectively (Table 2 ).

\section{Pregnancy dietary pattern Dietary patterns during pregnancy in women of childbearing age}

Factor analysis was used to extract four dietary patterns during pregnancy: "vegetarian pattern", "balance pattern", "traditional pattern" and "processing pattern". Food groups with high factor loadings on dietary pattern 1 included 3 kinds of vegetables, 4 kinds of fruits, pasta, rice/porridge, soy products, fungus mushrooms, it was worth noting that animal protein foods were absent in this model. Food groups with high factor loadings on dietary pattern 2 included 6 kinds of animal protein foods, 3 kinds of vegetables, pasta, rice/porridge, soy 
Table 1 Basic characteristics of the respondent

\begin{tabular}{|c|c|c|}
\hline Characteristics & $\mathrm{n}$ & result \\
\hline Mean maternal age, years $(\bar{x} \pm s)$ & 15,980 & $27.6 \pm 4.5$ \\
\hline Family monthly expenditure $(\stackrel{E}{E}, \bar{x} \pm s)$ & 15,980 & $2789.6 \pm 531.8$ \\
\hline \multicolumn{3}{|l|}{ Mother's place of residence (\%) } \\
\hline Urban & 3835 & 24.0 \\
\hline Rural & 12,145 & 76.0 \\
\hline \multicolumn{3}{|l|}{ Region (\%) } \\
\hline Southern Shaanxi Region & 4395 & 27.5 \\
\hline Northern Shaanxi Region & 2796 & 17.5 \\
\hline Middle Shaanxi Region & 8789 & 55.0 \\
\hline \multicolumn{3}{|l|}{ Educational levels (\%) } \\
\hline Elementary school and below & 1326 & 8.3 \\
\hline Junior high school & 7463 & 46.7 \\
\hline High school and secondary school & 3532 & 22.1 \\
\hline University degree and above & 3659 & 22.9 \\
\hline \multicolumn{3}{|l|}{ Occupation (\%) } \\
\hline Peasantry & 9940 & 62.2 \\
\hline Worker & 975 & 6.1 \\
\hline Private teacher & 368 & 2.3 \\
\hline Cadres and civil servants & 335 & 2.1 \\
\hline Business and service industry & 1806 & 11.3 \\
\hline Technicians and other intellectuals & 479 & 3.0 \\
\hline Soldier & 2077 & 13.0 \\
\hline Newborn age (month, $\bar{x} \pm s$ ) & 15,980 & $6.6 \pm 2.6$ \\
\hline \multicolumn{3}{|l|}{ Gender (\%) } \\
\hline Baby boy & 8501 & 53.2 \\
\hline Baby girl & 7479 & 46.8 \\
\hline Birth weight $(g, \bar{x} \pm s)$ & 15,980 & $3279.9 \pm 454.6$ \\
\hline
\end{tabular}

products, potatoes, fungus mushrooms, kelp seaweed, melon fruits, nuts, etc., which was characterized by a variety of foods. Dietary pattern 3 was characterized by high factor loadings for rice/porridge, pasta, steamed rice noddles, eggs, milk and dairy, soy products, potatoes, vegetables and fruits, etc. Dietary pattern 4 was characterized by high factor loadings for preserved foods and beverages, snacks, and also included a small amount of vegetables, soy products and staple foods. Among the four dietary structures, the vegetarian pattern was a predominant pattern, which explained the $13.63 \%$ of the variability in the predictors, and the latter three patterns explained $9.28,7.62$ and $5.96 \%$ of the variability in the predictors, respectively (Table 3 ).

\section{Dietary patterns during pregnancy were studied by LCA}

We chose 4 classes by LCA analysis because at which time the value of AIC (1307.28) and BIC (1311.01) were the smallest, the optimal model was obtained. This result was consistent with the classification of dietary patterns obtained by factor analysis. Figure 1 showed the intake of 14 foods in each dietary pattern (with the median intake as the limit, the group was divided into three groups: greater than, less than the median and no intake). The LCA-Traditional class had higher intake of cereals, potatoes, beans, vegetables, fruits, livestock and poultry, and eggs. The LCA-Balance class had higher intake of cereals, potatoes, beans, vegetables, fruits, fungus mushrooms, livestock and poultry meat, fish, shrimps, crabs, shellfish, milk, and nuts. The LCA-Vegetarian class had higher intake of cereals, beans, vegetables, fruits, livestock and poultry. The LCA-Processing class had higher intake of cereals, vegetables, snacks, instant food, and beverages.

\section{Social demographic factors affecting the classification of dietary patterns}

In this study, 5881 subjects were included in the vegetarian pattern, 4778 in the balance pattern, 4442 in the

Table 2 Newborn birth weight distribution $(N=15,980)$

\begin{tabular}{|c|c|c|c|c|c|c|c|c|c|c|c|c|c|}
\hline & \multirow[t]{3}{*}{$\bar{x} \pm s$} & \multicolumn{6}{|c|}{ Grouped by birth weight } & \multicolumn{6}{|c|}{ Grouped by birth weight and gestational age } \\
\hline & & \multicolumn{2}{|c|}{$<2500 \mathrm{~g}$} & \multicolumn{2}{|c|}{$2500 \sim 4000 \mathrm{~g}$} & \multicolumn{2}{|c|}{$>4000 \mathrm{~g}$} & \multicolumn{2}{|l|}{ SGA } & \multicolumn{2}{|l|}{ AGA } & \multicolumn{2}{|l|}{ LGA } \\
\hline & & $\mathrm{n}$ & $\%$ & $\mathrm{n}$ & $\%$ & $\mathrm{n}$ & $\%$ & $\mathrm{n}$ & $\%$ & $\mathrm{n}$ & $\%$ & $\mathrm{n}$ & $\%$ \\
\hline \multicolumn{14}{|l|}{ Area } \\
\hline Urban & $3339.2 \pm 461.6$ & 607 & 3.8 & 14,542 & 91.0 & 831 & 5.2 & 1998 & 12.5 & 12,464 & 78.0 & 1518 & 9.5 \\
\hline Rural & $3230.7 \pm 451.0$ & 943 & 5.9 & 14,462 & 90.5 & 575 & 3.6 & 2493 & 15.6 & 12,400 & 77.6 & 1087 & 6.8 \\
\hline \multicolumn{14}{|l|}{ Region } \\
\hline Southern Shaanxi Region & $3263.7 \pm 453.3$ & 783 & 4.9 & 14,526 & 90.9 & 671 & 4.2 & 2397 & 15.0 & 12,353 & 77.3 & 1230 & 7.7 \\
\hline Northern Shaanxi Region & $3290.3 \pm 464.7$ & 943 & 5.9 & 14,366 & 89.9 & 671 & 4.2 & 2525 & 15.8 & 12,400 & 77.6 & 1055 & 6.6 \\
\hline Middle Shaanxi Region & $3252.6 \pm 450.9$ & 703 & 4.4 & 14,542 & 91.0 & 735 & 4.6 & 1966 & 12.3 & 12,752 & 79.8 & 1262 & 7.9 \\
\hline Total & $3279.9 \pm 454.6$ & 783 & 4.9 & 14,494 & 90.7 & 703 & 4.4 & 2349 & 14.7 & 12,417 & 77.7 & 1214 & 7.6 \\
\hline
\end{tabular}


Table 3 Factor Analysis of Dietary Patters of Women of Childbearing Age ${ }^{a}$

\begin{tabular}{|c|c|c|c|c|c|c|c|}
\hline \multicolumn{2}{|c|}{ Factor 1:Vegetarian Pattern } & \multicolumn{2}{|c|}{ Factor 2:Balance Pattern } & \multicolumn{2}{|c|}{ Factor 3:Traditional Pattern } & \multicolumn{2}{|c|}{ Factor 4:Processing Pattern } \\
\hline Foods & $\begin{array}{l}\text { Factor } \\
\text { load }\end{array}$ & Foods & $\begin{array}{l}\text { Factor } \\
\text { load }\end{array}$ & Foods & $\begin{array}{l}\text { Factor } \\
\text { load }\end{array}$ & Foods & $\begin{array}{l}\text { Factor } \\
\text { load }\end{array}$ \\
\hline Pasta & 0.326 & Pasta & 0.425 & Rice/porridge & 0.486 & Pasta & 0.488 \\
\hline Rice/porridge & 0.318 & Rice/porridge & 0.379 & Pasta & 0.479 & Steamed rice noddles & 0.326 \\
\hline Bean products & 0.394 & Chicken/duck egg & 0.323 & $\begin{array}{l}\text { Steamed rice } \\
\text { noddles }\end{array}$ & 0.369 & Instant noodles & 0.587 \\
\hline Root vegetables & 0.551 & Chicken/duck & 0.338 & Potatoes & -0.402 & $\begin{array}{l}\text { Bacon / bacon / } \\
\text { sausage }\end{array}$ & -0.601 \\
\hline Melon vegetables & 0.586 & $\begin{array}{l}\text { Red meat, beef and } \\
\text { mutton }\end{array}$ & 0.326 & Mike and dairy & 0.326 & Bean products & 0.319 \\
\hline Green vegetables & 0.420 & Fish & 0.356 & Chicken/duck egg & 0.349 & Root vegetables & 0.328 \\
\hline $\begin{array}{l}\text { Fungus } \\
\text { mushrooms }\end{array}$ & 0.398 & Animal's guts & 0.329 & Bean products & 0.395 & Green vegetables & -0.396 \\
\hline Pome fruit & 0.652 & Mike and dairy & 0.498 & Pome fruit & -0.645 & Snacks & 0.556 \\
\hline Citrus fruit & 0.388 & Bean products & 0.486 & Citrus fruit & -0.519 & Nuts & -0.318 \\
\hline Berry fruit & 0.529 & Root vegetables & 0.571 & Root vegetables & 0.409 & Drink & 0.509 \\
\hline \multirow[t]{7}{*}{ Melon fruit } & 0.765 & Melon vegetables & 0.401 & Green vegetables & 0.569 & & \\
\hline & & Potatoes & 0.316 & Fungus mushrooms & 0.330 & & \\
\hline & & Green vegetables & 0.398 & & & & \\
\hline & & Fungus mushrooms & -0.405 & & & & \\
\hline & & Kelp seaweed & 0.369 & & & & \\
\hline & & Melon fruit & 0.468 & & & & \\
\hline & & Nuts & 0.392 & & & & \\
\hline \multicolumn{8}{|c|}{ Variance interpretation ratio (\%) } \\
\hline 13.63 & & 9.28 & & 7. 62 & & 5.96 & \\
\hline
\end{tabular}

${ }^{a}$ The principal component analysis method was used to extract the factor, and the variance maximization orthogonal method was used to rotate, and the factor load was obtained, and the food item with the absolute value of the retention factor load exceeding 0.3 was obtained

traditional pattern, and 879 in the processing pattern. The social demographic characteristics that had an impact on the classification of dietary patterns included family monthly expenditure $(P=0.018)$, the higher the monthly household expenditure, the more inclined the balance pattern and processing pattern, while the lower ones were more likely to choose the vegetarian pattern. Urban women were more inclined to choose balanced pattern, rural women were more inclined to choose vegetarian pattern $(P=0.020)$. The higher the education level of the mother, the more inclined to choose the balanced pattern, the lower the education level, the more inclined to vegetarian pattern and processing pattern $(P=$ 0.035). Women with gestational age of less than 37 weeks tended to choose the traditional model, while women with gestational age of more than 37 weeks tended to choose the balanced model $(P=0.003)$. Women in southern region mostly relied on balanced pattern and processing pattern, women in northern region were mostly based on traditional pattern, while women in middle region were mostly vegetarian pattern $(P<0.001)$ (Table 4).

\section{Nutrient intake under different dietary patterns}

Processing pattern (average energy intake was $2789 \pm$ $853 \mathrm{kcal}$ ) and balanced pattern (average energy intake was $2527 \pm 895 \mathrm{kcal}$ ) compared to traditional pattern (average energy intake was $2395 \pm 824 \mathrm{kcal}$ ) and vegetarian pattern (average energy intake was $2325 \pm 899 \mathrm{kcal}$ ), more easy to intake more energy $(P=0.005)$; balanced pattern (average protein intake of $78 \pm 9 \mathrm{~g}$ ) was more adequate than the other three groups of protein intake $(P<0.001)$; processing pattern (average carbohydrate intake was $389 \pm 133 \mathrm{~g}$ ) and traditional pattern (average carbohydrate intake was $377 \pm 137 \mathrm{~g}$ ) compared to the balanced pattern (average carbohydrate intake was $349 \pm 132 \mathrm{~g}$ ) and the vegetarian pattern (average carbohydrate intake was $369 \pm 126 \mathrm{~g}$ ), were more likely to intake more carbohydrate $(P=0.040)$; processing pattern (average cholesterol intake of $220 \pm 105 \mathrm{~g}$ ) was higher than the other three groups of cholesterol intake $(P<$ 0.001 ); balanced pattern (average vitamin A intake was $637 \pm 452 \mu \mathrm{gRE})$ was more adequate than the other three groups of vitamin A intake $(P=0.026)$; balanced pattern (average vitamin $B_{12}$ intake was $2.5 \pm 0.5 \mu \mathrm{g}$, average folic 

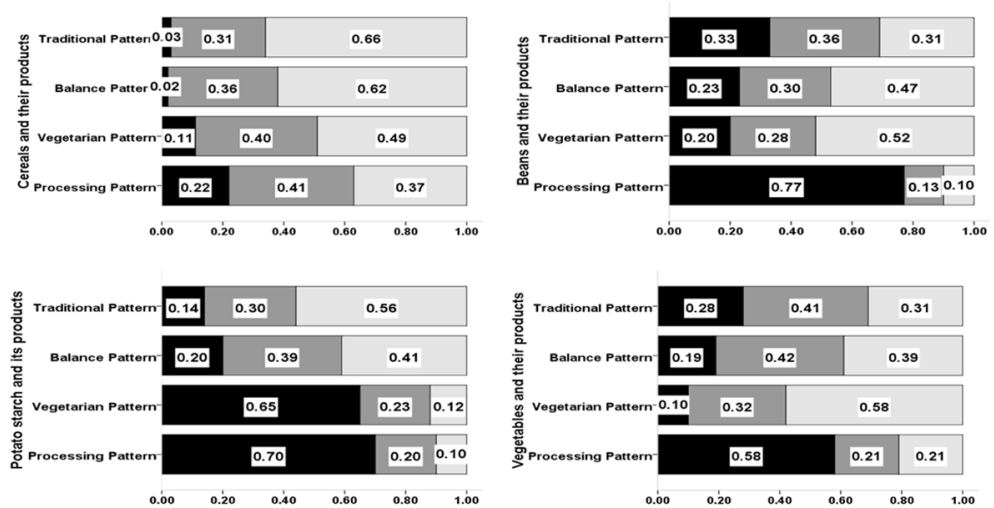

Intake $\square_{\text {No consumption }}$ <median $_{>\text {median }}$
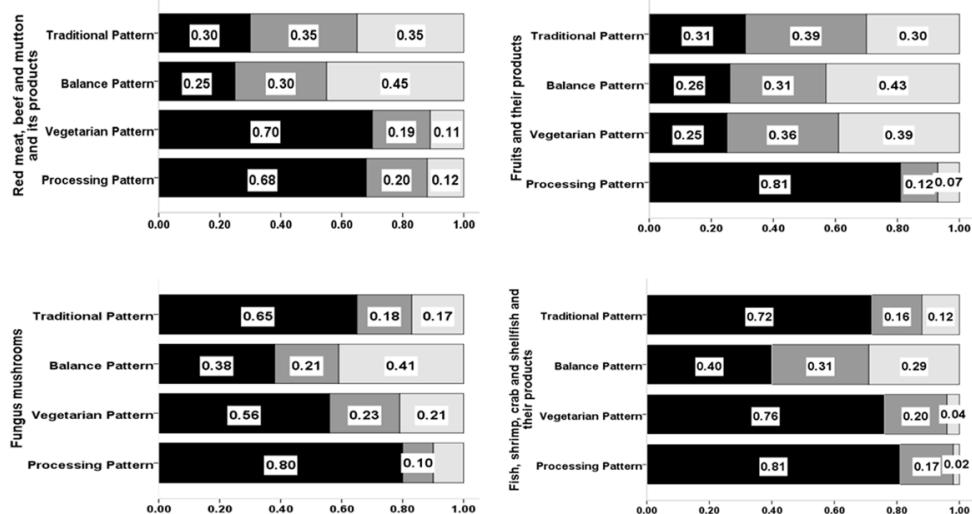

Intake $\square_{\text {No consumption } \square<\text { median } \quad>\text { median }}$
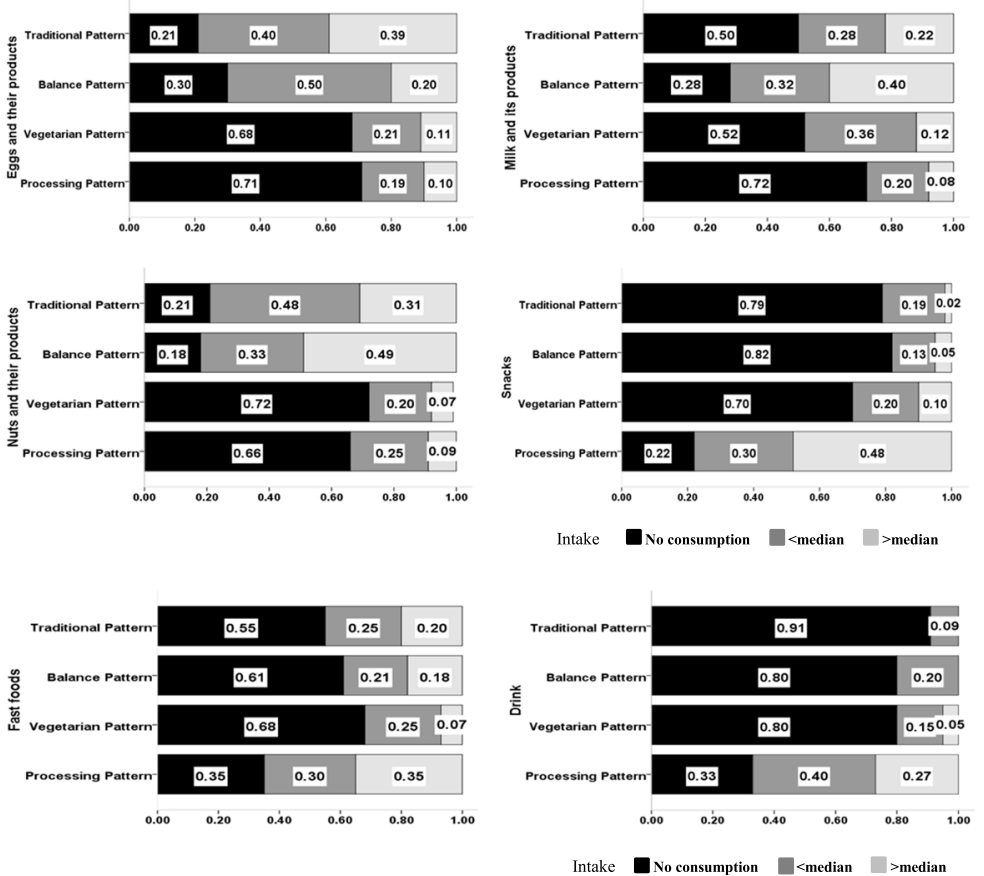

Fig. 1 Food intake under various dietary patterns 
Table 4 Social demographic factors affecting the classification of dietary patterns $(N=15,980)$

\begin{tabular}{|c|c|c|c|c|c|}
\hline Confounders & $\begin{array}{l}\text { Vegetarian Pattern } \\
(n=5881)\end{array}$ & $\begin{array}{l}\text { Balance Pattern } \\
(n=4778)\end{array}$ & $\begin{array}{l}\text { Traditional Pattern } \\
(n=4442)\end{array}$ & $\begin{array}{l}\text { Processing Pattern } \\
(n=879)\end{array}$ & $P$-Value \\
\hline Mean maternal age, (years, $\bar{x} \pm s$ ) & $27.6 \pm 4.8$ & $27.9 \pm 4.5$ & $27.5 \pm 4.5$ & $26.9 \pm 4.3$ & 0.530 \\
\hline Family monthly expenditure $(¥, \bar{x} \pm s)$ & $2277.4 \pm 361.5$ & $2889.6 \pm 431.7$ & $2331.2 \pm 226.4$ & $2555.3 \pm 389.2$ & 0.018 \\
\hline \multicolumn{6}{|l|}{ Mother's place of residence $(n(\%))$} \\
\hline Urban & $676(11.5)$ & $1209(25.3)$ & $817(18.4)$ & $200(22.8)$ & \multirow[t]{2}{*}{0.020} \\
\hline Rural & 5205(88.5) & $3569(74.7)$ & 3625(81.6) & $679(77.2)$ & \\
\hline \multicolumn{6}{|l|}{ Educational status (n(\%)) } \\
\hline Elementary school and below & 1594(27.1) & 879(18.4) & 1133(25.5) & $252(28.6)$ & \multirow[t]{4}{*}{0.035} \\
\hline Junior high school & $3564(60.6)$ & 879(18.4) & 1577(35.5) & $495(56.3)$ & \\
\hline High school and secondary school & $553(9.4)$ & 2399(50.2) & $1355(30.5)$ & $91(10.4)$ & \\
\hline University degree and above & $170(2.9)$ & $621(13.0)$ & $377(8.5)$ & $41(4.7)$ & \\
\hline \multicolumn{6}{|l|}{ Gender (n(\%)) } \\
\hline Baby boy & $3118(53.0)$ & 2551(53.4) & $2288(51.5)$ & $470(53.5)$ & \multirow[t]{2}{*}{0.488} \\
\hline Baby girl & 2763(47.0) & 2227(46.6) & 2154(48.5) & 409(46.5) & \\
\hline \multicolumn{6}{|l|}{ Newborn age (n(\%)) } \\
\hline$\leq 37$ weeks & $453(7.7)$ & $134(2.8)$ & 484(10.9) & $77(8.8)$ & \multirow[t]{2}{*}{0.003} \\
\hline$>37$ weeks & $5428(92.3)$ & $4644(97.2)$ & 3958(89.1) & 802(91.2) & \\
\hline \multicolumn{6}{|l|}{ Area $(n(\%))$} \\
\hline Southern Shaanxi Region & $541(9.2)$ & $1410(29.5)$ & 458(10.3) & 269(30.6) & \multirow[t]{3}{*}{$<0.001$} \\
\hline Northern Shaanxi Region & $1588(27.0)$ & $836(17.5)$ & $2021(45.5)$ & $180(20.5)$ & \\
\hline Middle Shaanxi Region & $752(63.8)$ & 2532(53.0) & 1963(44.2) & $430(48.9)$ & \\
\hline
\end{tabular}

acid intake was $559 \pm 227 \mu \mathrm{gDFE}$, average calcium intake was $906 \pm 365 \mathrm{mg}$ ) was higher than the other three groups of vitamin $\mathrm{B}_{12}$, folic acid, calcium intake $(P<$ 0.001 ); the balanced pattern (average iron intake was $33 \pm 12 \mathrm{mg}$ ) was more adequate than the other three groups of iron intake $(P=0.044)$. For other nutrients, there was no difference between the four dietary patterns (Table 5).

\section{The association between dietary patterns during pregnancy and neonatal birth weight}

Unstratified analysis, women in the lowest tertile of adherence to vegetarian pattern had lower risk of low birth weight in offspring compared with moderate tertile $(O R=0.67,95 \% C I: 0.46-0.98)$, women in the highest tertile increased the risk of low birth weight in offspring $(O R=1.82$, 95\%CI: $1.36-3.77)$, and the results remained unchanged after adjusting for covariates. In rural areas, vegetarian pattern was positively associated with a higher risk of low birth weight $(O R=1.61,95 \% C I$ : $1.06-2.93)$, the processing pattern was found a protective factor for the occurrence of low birth weight $(O R=0.98,95 \% C I$ : $0.43-$ 0.99). The same results were not shown in urban areas.

After stratification by region, compared with the moderate processing pattern, $\mathrm{T}_{1}$ and $\mathrm{T}_{3}$ groups in pregnant women could increase the risk of low birth weight in offspring in southern Shaanxi region, the $\mathrm{T}_{3}$ group was statistically significant $(O R=8.83,95 \% C I: 1.22-15.16)$. In northern Shaanxi region, the balanced pattern $\mathrm{T}_{1}$ group could increase the risk of low birth weight $(O R=1.35$, 95\%CI: 1.14-3.85), the $\mathrm{T}_{3}$ group reduced the risk of low birth weight $(O R=0.35,95 \% C I$ : $0.14-0.83)$. In middle region, women in the highest tertile of adherence to vegetarian pattern had higher risk of low birth weight in offspring $(O R=1.75,95 \% C I: 1.18-2.62)$. The traditional pattern $\mathrm{T}_{1}$ group could reduce the risk of low birth weight in offspring $(O R=0.80,95 \% C I$ : $0.39-0.93)$, the $\mathrm{T}_{3}$ group increased the risk of low birth weight $(O R=1.55$, 95\%CI: 1.05-3.75) (Table 6).

\section{Discussion}

The incidence of birth defects and low birth weight was high in Shaanxi, China [18], but there was a lack of effective evaluation of the dietary patterns that dominated local women of childbearing age during pregnancy and their impact on newborn birth weight. This study evaluated the effects of different dietary patterns on neonatal birth weight, and provided a theoretical and practical reference for dietary nutrition interventions to improve women's dietary patterns during pregnancy and reduce abnormal birth weight in Shaanxi Province, China. 
Table 5 Mean (standard deviation) of daily absolute nutrient intakes according to clusters of dietary patterns among 15,980 pregnant women $(\bar{x} \pm s)$

\begin{tabular}{|c|c|c|c|c|c|}
\hline & Vegetarian Pattern & Balance Pattern & Traditional Pattern & Processing Pattern & $P$-Value \\
\hline Energy (Kcal) & $2325 \pm 899$ & $2527 \pm 895$ & $2395 \pm 824$ & $2789 \pm 853$ & 0.005 \\
\hline Protein (g) & $60 \pm 12$ & $78 \pm 9$ & $65 \pm 10$ & $58 \pm 8$ & $<0.001$ \\
\hline Fat (g) & $68 \pm 9$ & $70 \pm 6$ & $69 \pm 8$ & $75 \pm 10$ & 0.052 \\
\hline Carbohydrate (g) & $369 \pm 126$ & $349 \pm 132$ & $377 \pm 137$ & $389 \pm 133$ & 0.040 \\
\hline Insoluble fiber (g) & $33 \pm 10$ & $31 \pm 11$ & $31 \pm 11$ & $28 \pm 12$ & 0.088 \\
\hline Cholesterol (g) & $50 \pm 40$ & $200 \pm 100$ & $110 \pm 60$ & $220 \pm 105$ & $<0.001$ \\
\hline Total vitamin A ( $\mu g R E)$ & $521 \pm 389$ & $637 \pm 452$ & $529 \pm 353$ & $520 \pm 376$ & 0.026 \\
\hline Carotene $(\mu \mathrm{g})$ & $2531 \pm 2167$ & $2908 \pm 2243$ & $2729 \pm 2238$ & $2482 \pm 2096$ & 0.153 \\
\hline Thiamine (mg) & $1.1 \pm 0.2$ & $1.2 \pm 0.3$ & $1.0 \pm 0.2$ & $0.9 \pm 0.4$ & 0.189 \\
\hline Riboflavin (mg) & $1.2 \pm 0.5$ & $1.3 \pm 0.4$ & $1.2 \pm 0.4$ & $1.2 \pm 0.5$ & 0.353 \\
\hline Vitamin $B_{6}(\mathrm{mg})$ & $1.5 \pm 0.6$ & $1.7 \pm 0.5$ & $1.5 \pm 0.5$ & $1.3 \pm 0.6$ & 0.226 \\
\hline Vitamin $B_{12}(\mu \mathrm{g})$ & $1.2 \pm 0.4$ & $2.5 \pm 0.5$ & $1.7 \pm 0.6$ & $1.0 \pm 0.5$ & $<0.001$ \\
\hline Folic acid ( $\mu g D F E)$ & $293 \pm 174$ & $559 \pm 227$ & $325 \pm 215$ & $278 \pm 202$ & $<0.001$ \\
\hline Nicotinic acid (mg) & $15 \pm 7$ & $16 \pm 9$ & $16 \pm 7$ & $15 \pm 7$ & 0.338 \\
\hline Vitamin C (mg) & $98 \pm 64$ & $109 \pm 75$ & $97 \pm 67$ & $95 \pm 63$ & 0.067 \\
\hline Vitamin E (mg) & $10 \pm 3$ & $11 \pm 4$ & $10 \pm 4$ & $9 \pm 3$ & 0.157 \\
\hline Calcium (mg) & $614 \pm 335$ & $906 \pm 365$ & $758 \pm 352$ & $622 \pm 351$ & $<0.001$ \\
\hline Phosphorus(mg) & $942 \pm 554$ & $1082 \pm 600$ & $995 \pm 533$ & $1210 \pm 613$ & 0.088 \\
\hline Potassium (mg) & $2413 \pm 121$ & $2557 \pm 140$ & $2535 \pm 128$ & $2665 \pm 146$ & 0.076 \\
\hline Sodium(mg) & $2502 \pm 212$ & $2659 \pm 235$ & $2889 \pm 253$ & $3003 \pm 267$ & 0.055 \\
\hline Magnesium(mg) & $405 \pm 193$ & $432 \pm 202$ & $423 \pm 198$ & $402 \pm 189$ & 0.565 \\
\hline Iron (mg) & $22 \pm 10$ & $33 \pm 12$ & $25 \pm 11$ & $20 \pm 10$ & 0.044 \\
\hline Zinc (mg) & $6.5 \pm 4.1$ & $7.6 \pm 4.4$ & $6.9 \pm 3.9$ & $6.2 \pm 3.8$ & 0.259 \\
\hline Selenium(mg) & $34 \pm 25$ & $40 \pm 28$ & $36 \pm 26$ & $32 \pm 21$ & 0.287 \\
\hline Copper(mg) & $2.0 \pm 1.0$ & $2.2 \pm 1.2$ & $2.1 \pm 1.1$ & $2.2 \pm 1.1$ & 0.474 \\
\hline lodine(mg) & $211 \pm 98$ & $228 \pm 108$ & $220 \pm 101$ & $225 \pm 112$ & 0.293 \\
\hline
\end{tabular}

At present, there are few studies on the dietary patterns of women of childbearing age during pregnancy, especially in China, where there are hardly any studies on the relationship between dietary patterns and newborn birth weight. In a cohort study in Denmark, the "Mediterranean pattern" reduced the risk of preterm birth; the "Western pattern" was positively associated with the occurrence of forearm fractures, low birth weight, and SGA in the offspring [19]. In this study, four dietary patterns were extracted by factor analysis: "vegetarian pattern", "balance pattern", "traditional pattern" and "processing pattern". The vegetarian pattern was a predominant pattern, characterised by a high intake of vegetables, fruits, soy products and staple foods, with a limited range of variety of foods and a lack of meat and eggs and dairy foods. Long-term use of this kind of dietary pattren could lead to insufficient intake of protein, especially high-quality protein and fat, especially essential fatty acids and vitamin A, calcium, iron, zinc, etc., which caused a series of health problems for mothers and their offspring. The balanced pattern was considered to be reasonable in food mix and suitable for various nutrients. It was recommended that pregnant women should adhere to this dietary pattern for a long time.

Some nutritional epidemiological studies had evaluated the relationship between dietary patterns and sociodemographic characteristics of the population [20-23]. On the basis of factor analysis, this study used LCA to analyze the social demography factors affecting various dietary patterns. The study found that the higher the monthly household expenditure, the more inclined to choose the balance pattern and processing pattern, while the lower ones were more likely to choose the vegetarian pattern; the higher the education level of the mother, the more inclined to choose the balanced pattern, the lower the education level, the more inclined to vegetarian pattern and processing pattern. A Norwegian study on dietary patterns in pregnant women also found that 


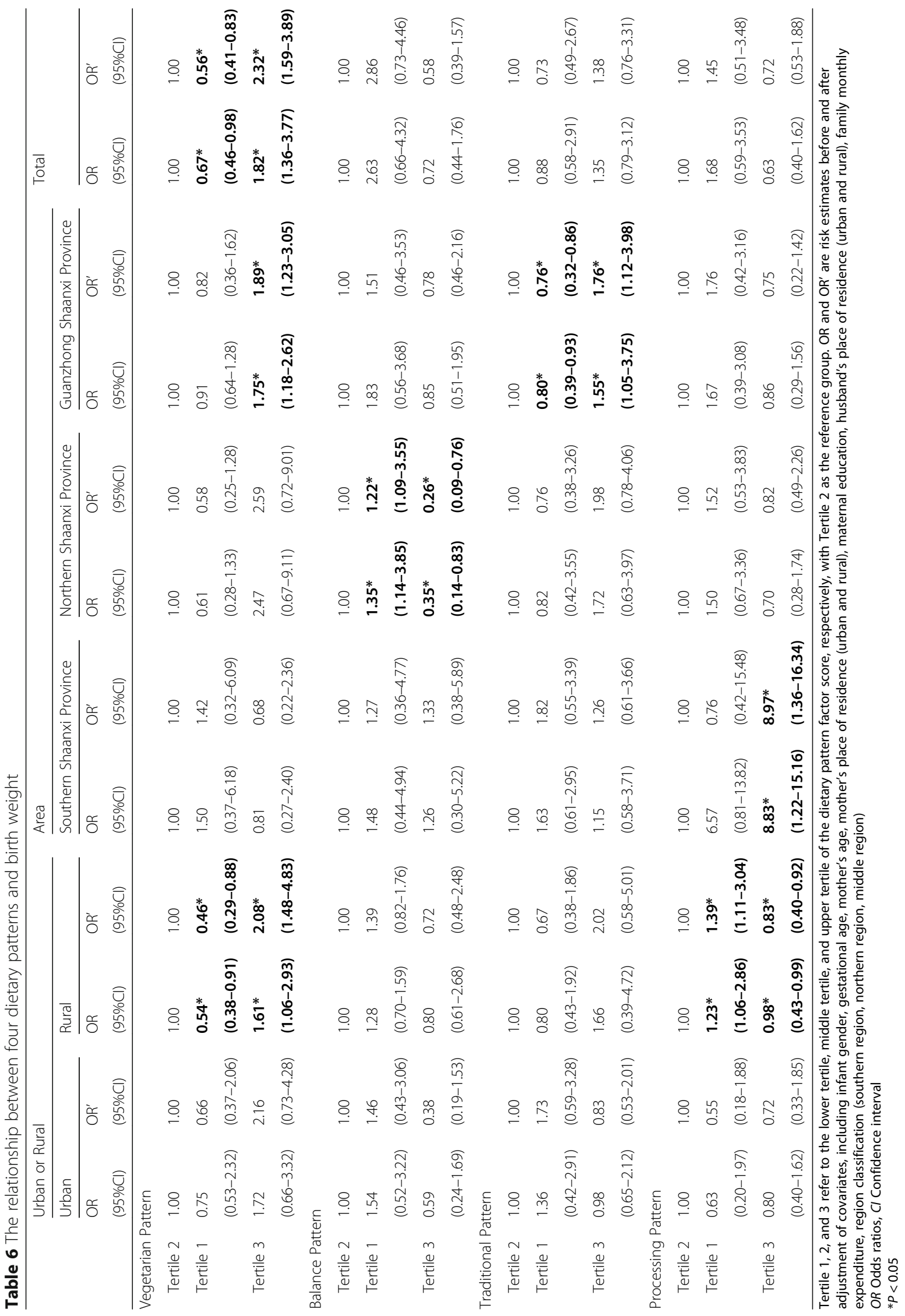


people with higher levels of education and household income tend to choose a balanced pattern rich in vegetables, fruits, nuts, milk, fish and whole grains [24]. Similar results were obtained in several other studies [25-27]. For the special group of pregnant women, in the traditional Chinese concept, people should ate more eggs and meat to supplement nutrition during pregnancy, and those with higher education level were often more health-conscious and had the financial ability to bear foods rich in nutrients [5]. The group with higher education level and economic income level was more inclined to adopt a balanced pattern.Urban women were more inclined to choose balanced pattern, rural women were more inclined to choose vegetarian pattern. A survey of dietary patterns of women in nine provinces in China found that women in rural areas and with low education levels were more likely to choose the potato or vegetarian pattern [28]. This might be related to the wide range of vegetable and potato food sources in rural areas and relatively economically.Women with gestational age of less than 37 weeks tended to choose the traditional model, while women with gestational age of more than 37 weeks tended to choose the balanced model. This was also consistent with the results of relevant reports that pregnant women with traditional dietary patterns were more prone to preterm birth [29]. Women in southern region mostly relied on balanced pattern and processing pattern, women in northern region were mostly based on traditional pattern, while women in middle region were mostly vegetarian pattern, which might be related to the fact that dietary pattern selection was population specific and susceptible to the influence of social culture and food supply [30-32]. The intake of nutrients varied among various dietary patterns, mainly due to the different types of foods contained in various dietary patterns.

This study found that in the unstratified and stratified rural areas and middle region, the incidence of low birth weight of newborns was positively correlated with the score of vegetarian-pattern diet, and the pregnant women with high scores in the traditional pattern also had an increased risk of low birth weight in middle region. Women who adopted these two dietary patterns were prone to cause insufficient intake of energy, protein, essential fatty acids, fat-soluble vitamins, and minerals rich in animal foods such as iron, calcium, and zinc, resulting in fetal growth disorders and affecting normal organ and tissue functions. However, a study in New Zealand showed that the higher the scores of traditional patterns (mainly fruits, vegetables, yogurt and lean meat) in early pregnancy, the lower the incidence of low birth weight [33], possibly due to the fact that our study contains different foods from the traditional patterns defined in this paper. In addition, the processing pattern was found a protective factor for the occurrence of low birth weight in rural areas, but women with high scores in the processing pattern had an increased risk of low birth weight in southern region. This dietary pattern had very few types of food, it was not only lack of foods rich in quality protein such as poultry, fish, shrimps and eggs, but also the staple food was only pasta, the vegetables and fruits were ingested less, and the pickled foods and snacks and drinks were more ingested. So not only lack of nutrients such as protein and unsaturated fatty acids, but also a variety of vitamins, such as vitamin A, B vitamins, vitamin $E$, vitamin $C$, etc., and increased the intake of a variety of harmful substances. It was not only unable to meet the nutritional needs of pregnant women, but also far from meeting the needs of fetal growth and development as well as the formation of tissues and organs, which leaded to the stop of fetal intrauterine development, the occurrence of low birth weight, and even premature separation of fetus and placenta [34], leading to reduced survival rate, spontaneous abortion and stillbirth. In rural areas, the reason for the opposite result might be that the sources of snacks, sweet foods, fast foods, and processed foods were few and not easy to obtain, women had eaten such foods during pregnancy, but the amount of consumption was small, such foods contained a lot of calories, so they could increase the birth weight of newborns. The high-scoring balanced pattern was a protective factor for the occurrence of low birth weight in northern areas. Under this dietary pattern, pregnant women were less likely to suffer from malnutrition, and their dietary intake could meet the nutritional needs of the mother and the fetus, and could reduce the occurrence of various adverse pregnancy outcomes, including abnormal birth weight of newborns [35]. Studies by Knudsen [36] had also shown that healthy dietary patterns rich in fruits, vegetables, and meat could significantly reduce the risk of SGA compared to western dietary patterns (high-fat milk, refined grains, and processed meat). A large sample study in Norway $(n=66,000)$ showed that pregnant women who adhered to a prudent diet during pregnancy (mainly fruits, vegetables, vegetable oils and whole grains) had a lower risk of preterm labor than other pregnant women [24]. Although the dietary patterns that favor birth outcomes varied from study to study, they were also consistent that eating low-processed foods such as fruits and vegetables, low-fat milk and lean meat during pregnancy might reduce the risk of low birth weight [37-39].

In summary, the dietary pattern of women of childbearing age may be closely related to the birth weight of the offspring. In order to reduce the occurrence of abnormal birth weight, women should adhere balance pattern during pregnancy, increasing the intake of high quality protein food, especially milk and seafood. It is suggested that dietary intervention during pregnancy 
should be improved, health education for dietary nutrition should be strengthened, and women should be able to make reasonable meals according to the actual local food supply characteristics. The advantage of this research is that the survey has undergone rigorous scientific design, the quality of the investigators is high, and the on-site work is organized and planned, the collected data is relatively accurate. The sample size of this study is large, and the possible confounding factors are controlled as much as possible during the analysis, increasing the reliability of the conclusion. However, there are still some limitations in this study. First of all, this study mainly adopts the cross-sectional research method, which cannot verify the causal relationship. Secondly, in this study, dietary information during pregnancy was recalled by subjects and collected through FFQ, which suggests that the recall bias could not be avoided. Thirdly, it is subjective to define the dietary pattern according to the concentration of food types contained in the dietary pattern, but the FFQ survey still has important reference value for the study of the dietary structure and food types of the population, especially the factor analysis plays a good role in the classification of dietary pattern [40-43]. Finally, some potential confounding factors may not be controlled during the analysis. This study used dietary patterns to estimate the effect on neonatal birth weight based on population level, providing important research clues for the relationship between dietary patterns of pregnant women and neonatal birth weight, and expanding new ideas. The results of the study will have important reference significance for prepregnancy counseling and prenatal care.

\section{Conclusion}

There are four kinds of dietary patterns in the pregnant women of childbearing age in Shaanxi Province, "vegetarian pattern" is predominant, and the dietary structure needs to be improved. The vegetarian and traditional pattern may be positively related to a higher risk of low birth weight while the balanced pattern may keep birth weight of offspring within the appropriate range. Health education of balanced diet and individual nutrition guidance during pregnancy should be strengthened, in order to make dietary structure during pregnancy are more reasonable, reduce the occurrence of adverse birth weight of newborns.

\footnotetext{
Acknowledgements

Thanks to my mentor, Mr. Dang Shaonong, who helped me a lot through suggestions, comments and criticism. His encouragement and firm support helped me through setbacks and frustrations. Without his urging, this dissertation would be impossible to complete. In addition, I am very grateful to the teachers and students of the Department of Health Statistics, School of Public Health, Xi'an Jiaotong University for their contributions to this paper in various ways.
}

Authors' contributions

Hui Yan: Conceptualization, Methodology, Software, Writing- Original draft preparation, Writing - Review \& Editing, Investigation, Data curation. Shaonong Dang: Formal analysis, Data curation, Resources, Writing - Review \& Editing, Project administration, Funding acquisition, Validation. Yaodong Zhang: Visualization, Investigation, Data curation, Project administration, Resources, Funding acquisition. Shuying Luo: Supervision, Investigation, Validation. The author(s) read and approved the final manuscript.

\section{Funding}

Project of birth defect control and prevention in

Shaanxi(Sxwsjswzfcght2016-013); National Natural Science Foundation of China (81230016).

\section{Availability of data and materials}

The data sets supporting the results of this article are included within the article and its additional files.

\section{Ethics approval and consent to participate}

The investigation was approved by the Medical Bioscience Research Ethics Committee of the Ministry of Medicine of Xi'an Jiaotong University (No.

2012008), and all respondents signed informed consent.

\section{Consent for publication}

All participants and authors agree to publish this article.

\section{Competing interests}

Not applicable.

\section{Author details}

${ }^{1} T$ The Children's Hospital Affiliaten to Zhengzhou University; Henan Children's Hospital, Zhengzhou Children's Hospital, Zhengzhou 450018, China. ${ }^{2}$ School of Public Health, Xi'an Jiaotong University, Xi'an 710061, China.

Received: 2 March 2020 Accepted: 17 August 2020

Published online: 26 August 2020

\section{References}

1. Herring CM, Bazer FW, Johnson GA, et al. Impacts of maternal dietary protein intake on fetal survival, growth, and development. Exp Biol Med. 2018;243(6):525-33.

2. Hu R, Wenli Z, Cuiling F, et al. Establishment of dietary patterns of pregnant women and related factors. China Public Health. 2015;31(11):1457-9. https://doi.org/10.11847/zgggws2015-31-11-27.

3. Dörsam Annica F, Hubert P, Nadia M, et al. The impact of maternal eating disorders on dietary intake and eating patterns during pregnancy: a systematic review. Nutrients. 2019;11(4):840-63.

4. HU FB. Dietary pattern analysis: a new direction in nutritional epidemiology. Curr Opin Lipidol. 2002;13(1):3-9. https://doi.org/10.1097/00041433200202000-00002.

5. Chen X, Zhao D, Mao X, et al. Maternal dietary patterns and pregnancy outcome. Nutrients. 2016;8(6):351-77.

6. Abdulai A, Albrecht J. Maternal dietary patterns and practices and birth weight in northern Ghana. PLoS One. 2016;11(9):85-102.

7. Ai-Ru C, Ling-Wei C, Shi LJ, et al. Maternal dietary patterns and birth outcomes: a systematic review and meta-analysis. Adv Nutr. 2019;10(4):68595 .

8. Arkkola T, Uusitalo U, Kronberg-Kippilä C, et al. Seven distinct dietary patterns identified among pregnant Finnish women - associations with nutrient intake and socio-demographic factors. Public Health Nutr. 2008; 11(2):176-82.

9. Thompson JM, Wall C, Becroft DM, et al. Maternal dietary patterns in pregnancy and the association with small-for-gestational-age infants. Br J Nutr. 2010;103(11):1665-73.

10. Knudsen VK, Orozova-Bekkevold IM, Mikkelsen TB, et al. Major dietary patterns in pregnancy and fetal growth. Eur J Clin Nutr. 2008;62(4):463-70.

11. Linda E-Ö, Lise BA, Julius J, et al. Associations between maternal dietary patterns and infant birth weight, small and large for gestational age in the Norwegian mother and child cohort study. Eur J Clin Nutr. 2019;73(9):127082. 
12. Christine $H$, Lubowa A. Simple methods to obtain food listing and portion size distribution estimates for use in semi-quantitative dietary assessment methods. PLoS One. 2019;14(10):379-93.

13. Yatiman $\mathrm{NH}$, Choo AL, Fendy $\mathrm{Y}$, et al. Validity and reliability of a food frequency questionnaire (FFQ) to assess dietary intake of preschool children. Int J Environ Res Public Health. 2019:16(23):4722-33.

14. Jie L. Obstetrics and Gynecology [M]. 8 version. Beijing: People's Medical Publishing House; 2013. p. 47-58.

15. Ikem E, Halldorsson Tl, Birgisdóttir BE, et al. Dietary patterns and the risk of pregnancy-associated hypertension in the Danish National Birth Cohort: a prospective longitudinal study. BJOG Int J Obstet Gynaecol. 2019;1(24):66373.

16. Livingstone KM, Mcnaughton SA. Association between diet quality, dietary patterns and cardiometabolic health in Australian adults: a cross-sectional study. Nutr J. 2018;17(1):19-32.

17. Ramkripa R, Carol D, Kingshipp Brittany L, et al. Dietary patterns before and during pregnancy and maternal outcomes: a systematic review. Am J Clin Nutr. 2019;109(Suppl_7):729-56

18. Haida D, Xiaofeng Z, Ruhai B, et al. Analysis of the occurrence of giant children and its influencing factors. J Xi'an Jiaotong Univ (Medical Edition). 2017;6:888-91.

19. Tielemans MJ, Erler NS, Leermakers E, et al. A priori and a posteriori dietary patterns during pregnancy and gestational weight gain: the generation $\mathrm{R}$ study. Nutrients. 2015;7(11):9383-99.

20. Teixeira JA, Castro TG, Grant CC, et al. Dietary patterns are influenced by socio-demographic conditions of women in childbearing age: a cohort study of pregnant women. BMC Public Health. 2018;18(1):301-15.

21. Ferreira CAA, Bartira G, Araujo TJ, et al. Dietary patterns in internal migrants in a continental country: a population-based study. PLoS One. 2017;12(10): 882-95.

22. Ewelina W, Agnieszka J, Elżbieta T, et al. Sociodemographic, lifestyle, environmental and pregnancy-related determinants of dietary patterns during pregnancy. Int J Environ Res Public Health. 2019;16(5):754-69.

23. Pozza SL, Formoso AMC, Alicia M, et al. Dietary intake patterns of children aged 6 years and their association with socioeconomic and demographic characteristics, early feeding practices and body mass index. BMC Public Health. 2016;16(1):1055-67.

24. Torgersen L, Ystrom E, Siega-Riz AM, et al. Maternal eating disorder and infant diet. A latent class analysis based on the Norwegian mother and child cohort study (MoBa). Appetite. 2015;84(3708):291-8.

25. Ina-Merle $D$, Brigitte $B$, Angelique $G$, et al. Determinants of dietary patterns and diet quality during pregnancy: a systematic review with narrative synthesis. Public Health Nutr. 2017;20(6):1009-28.

26. Appannah G, Pot GK, Oddy WH, et al. Determinants of a dietary pattern linked with greater metabolic risk and its tracking during adolescence. J Hum Nutr Diet. 2018;31(2):218-27.

27. Josune $\mathrm{O}$, de Victoria Emilio $\mathrm{M}$, Javier $\mathrm{A}-\mathrm{B}$, et al. Adequacy of critical nutrients affecting the quality of the Spanish diet in the ANIBES study. Nutrients. 2019;11(10):2328-45.

28. Jiguo Z, Bing Z, Wang $H$, et al. Study on dietary patterns of adult women in 9 provinces of China. Chinese J Epidemiol. 2013;34(1):37-40.

29. Lu M-S, He J-R, Qiaozhu C, et al. Maternal dietary patterns during pregnancy and preterm delivery: a large prospective cohort study in China. Nutr J. 2018;17(1):71-81.

30. Gete Dereje G, Michael W, Mishra Gita D. Prepregnancy dietary patterns and risk of preterm birth and low birth weight: findings from the Australian longitudinal study on Women's health. Am J Clin Nutr. 2020;111(5):1048-58.

31. Ai-Ru C, de Seymour JV, Marjorelee C, et al. A vegetable, fruit, and white rice dietary pattern during pregnancy is associated with a lower risk of preterm birth and larger birth size in a multiethnic Asian cohort: the growing up in Singapore towards healthy outcomes (GUSTO) cohort study. Am J Clin Nutr. 2016;104(5):1416-23

32. Zerfu Taddese A, Melaku U, Kaleab B. Dietary diversity during pregnancy is associated with reduced risk of maternal anemia, preterm delivery, and low birth weight in a prospective cohort study in rural Ethiopia. Am J Clin Nutr. 2016;103(6):1482-8.

33. Poon AK, Edwina $Y$, Nansi B, et al. Maternal dietary patterns during third trimester in association with Birthweight characteristics and early infant growth. Scientifica (Cairo). 2013;70(28):09-16
34. Hoover Elizabeth A, Louis JM. Optimizing health: weight, exercise, and nutrition in pregnancy and beyond. Obstet Gynecol Clin N Am. 2019;46(3): 431-40.

35. Lu M-S, Qiao-Zhu C, He J-R, et al. Maternal dietary patterns and fetal growth: a large prospective cohort study in China. Nutrients. 2016;8(5):25770.

36. Garay Samantha M, Savory Katrina A, Lorna S, et al. The grown in Wales study: examining dietary patterns, custom birthweight centiles and the risk of delivering a small-for-gestational age (SGA) infant. PLoS One. 2019;14(3): 412-25.

37. Emond Jennifer A, Karagas Margaret R, Baker Emily R, et al. Better diet quality during pregnancy is associated with a reduced likelihood of an infant born small for gestational age: an analysis of the prospective New Hampshire birth cohort study. J Nutr. 2018;148(1):22-30.

38. Katarzyna MB, Katarzyna EP, Jakub M. Association between maternal dietary patterns and anthropometric parameters of polish pregnant women and infants: a cross-sectional study. J Food Nutr Res. 2017;5(11):824-31.

39. de Lima Pereira CN, Barbosa CD, Pereira EAP, et al. Dietary patterns in pregnancy and birth weight. Revista de Saude Publica. 2015;49(10):62-72.

40. Grieger JA, Grzeskowiak LE, Bianco-Miotto T, et al. Pre-pregnancy fast food and fruit intake is associated with time to pregnancy. Hum Reprod. 2018; 33(6):1063-70.

41. Silva-Jaramillo Katherine M, Neutzling Marilda B, Michele D. FFQ for the adult population of the capital of Ecuador (FFQ-Quito): development, reliability and validity. Public Health Nutr. 2015;18(14):2540-9.

42. Khaoula EK, Vanessa G-L, Mohamed K, et al. Adaptation and validation of a food frequency questionnaire (FFQ) to assess dietary intake in Moroccan adults. Nutr J. 2018;17(1):61-73.

43. Anne $A B$, Ingi $H T$, Inge $T$, et al. Correction: Mother's dietary quality during pregnancy and offspring's dietary quality in adolescence: follow-up from a national birth cohort study of 19,582 mother-offspring pairs. PLoS Med. 2019;16(11):911-28.

\section{Publisher's Note}

Springer Nature remains neutral with regard to jurisdictional claims in published maps and institutional affiliations.
Ready to submit your research? Choose BMC and benefit from:

- fast, convenient online submission

- thorough peer review by experienced researchers in your field

- rapid publication on acceptance

- support for research data, including large and complex data types

- gold Open Access which fosters wider collaboration and increased citations

- maximum visibility for your research: over $100 \mathrm{M}$ website views per year

At $\mathrm{BMC}$, research is always in progress.

Learn more biomedcentral.com/submissions 